\title{
Talanta
}

\section{Radiosensitivity study of cefazolin sodium}

\author{
A.-S. Crucq, C. Slegers, V. Deridder, B. Tilquin * \\ Unité d'Analyse Chimique et Physico-Chimique des Médicaments, UCL-7230, unité CHAM - \\ Université Catholique de Louvain 72, Avenue E. Mounier, B-1200 Louvain en Woluwe, Bruxelles, Belgium
}

Received 22 June 1999; received in revised form 29 February 2000; accepted 5 May 2000

\begin{abstract}
The extent of physico-chemical changes induced by irradiation of cefazolin sodium was investigated. The methods used were potency determination, impurity profile, colour measurements and $\mathrm{pH}$ measurements. The potency of irradiated samples at $25 \mathrm{kGy}$ was $4 \pm 2 \%$ lower than that of the non irradiated ones. The total amount of related substances increased from $0.72 \pm 0.01 \%$ in the non irradiated samples to $4.9 \pm 0.7 \%$ in the samples irradiated at 25 $\mathrm{kGy}$. Most of the peaks showed trace amounts $(<0.01 \%)$, the largest one represented $1.2 \pm 0.5 \%$ of the total related substances. Only two peaks were identified by chromatography: the methyl-1,2,3-thiazol-2 thiol-5 and the 7aminocephalosporanic acid. The latter related substance is only produced by the irradiation of cefazolin sodium. The $\mathrm{pH}$ values of the samples were within the specifications of the European Pharmacopoeia. The colour of the cefazolin sodium powder changed from white to yellow upon irradiation. The yellow colour persisted after the dissolution of the powder. Most of the tests carried out met the Pharmacopoeia's specifications, except the one concerning the colour of the solution. (C) 2000 Elsevier Science B.V. All rights reserved.
\end{abstract}

Keywords: Cefazolin sodium; Radiosterilization; $\gamma$ Radiation; Analysis

\section{Introduction}

There is considerable interest regarding the treatment of pharmaceuticals by ionizing radiation because of the clear advantages this process offers compared to other methods of sterilization. This process can be carried out on the packaged product and is applicable to heat sensitive prod-

\footnotetext{
* Corresponding author. Tel.: + 32-2-7647231; fax: + 32-27647296.

E-mail address: tilquin@cham.ucl.ac.be (B. Tilquin).
}

ucts. Radiation processing is clean and well controlled as described by Dam et al. (1995) [1]. The only important parameter to control is the dose required to achieve sterilization, as reported by Jacobs (1983) [2].

The main concern with the use of ionizing radiation to sterilize pharmaceuticals is the formation of products by radiolysis that may affect the drug quality.

In this study, we investigated the extent of physico-chemical changes that occurred after irradiation of cefazolin sodium, a semi-synthetic cephalosporin. 


\section{Experimental part}

Cefazolin sodium was supplied by Eli Lilly as the freeze-dried product, Kefzol ${ }^{\circledR}$. Its structure is presented in Fig. 1.

\subsection{Irradiation}

Irradiation was performed on Kefzol ${ }^{\circledR}$ (freezedried material), in a Gammacell 220 and in a high energy electron accelerator. Glass vials of about 2 $\mathrm{g}$ of Kefzol ${ }^{\circledR}$ were irradiated. With the Gammacell 220 , the dose rate was about $10 \mathrm{~Gy} \mathrm{~s}^{-1}$ and the dose ranged from 2 to $30 \mathrm{kGy}$. The high energy electron accelerator (Linac) named CIRCE II, produced electrons with an energy of $9.5 \pm 0.4$ $\mathrm{MeV}$ and has a power of $20 \mathrm{~kW}$. The electrons were delivered at a rate of 480 pulses per second with a pulse width of $12 \mu \mathrm{s}$. The average current was $\approx 2 \mathrm{~mA}$ and the dose ranged from 15 to 35 $\mathrm{kGy}$. The irradiations were performed three times.

\subsection{Potency determination}

The potency was determined by HPLC following Eli Lilly's procedures. The following HPLC system was used: Pump Spectra-Physics SP8800; Autosampler SP8880 with injection loop of $20 \mu$; variable wavelength detector Spectra 100. Analytical column Ultrasphere ODS $5 \mu \mathrm{m}, 4.6 \mathrm{~mm} \times 15$ $\mathrm{cm}$; column heater: $30^{\circ} \mathrm{C}$; mobile phase: acetonitrile, triethylamine solution $(10 \mathrm{ml} / \mathrm{l})$ adjusted at pH 2.5 with phosphoric acid (9:91); flow rate: 2 $\mathrm{ml} / \mathrm{min}$.; UV detection at $220 \mathrm{~nm}$.

\subsection{Samples}

Samples were prepared by weighing $25 \mathrm{mg}$ of $\mathrm{Kefzol}^{\circledR}$ into a $50 \mathrm{ml}$ volumetric flask and diluting with mobile phase.

\subsection{Impurity profile determination}

The impurity profile was determined by HPLC. Stability indicating analytical method was supplied by the Eli Lilly Company. The following validated chromatographic conditions were used:

Analytical column: Merck LiChroSphere 100 RP-18 $5 \mu \mathrm{m}, 4.6 \mathrm{~mm} \times 25 \mathrm{~cm}$; column heater: $30^{\circ} \mathrm{C}$; mobile phase: gradient acetonitrile-buffer (786 mg diethylamine $\mathrm{HCl}, 2.4 \mathrm{~g}$ sodium phosphate monobasic monohydrate into $11, \mathrm{pH}$ adjusted to 2.5 with phosphoric acid). Initial composition of the mobile phase: $100 \%$ buffer. To obtain the final composition of the mobile phase: acetonitrile-buffer (30:70), the $\%$ of acetonitrile was increased linearly at a rate of $1 \% / \mathrm{min}$. This composition was held for an additional $10 \mathrm{~min}$; UV detection at $220 \mathrm{~nm}$ and scanned from 210 to $600 \mathrm{~nm}$ using a Beckman Diode Array detector. Samples were prepared by weighing $50 \mathrm{mg}$ of $\mathrm{Kefzol}^{\circledR}$ into a $10 \mathrm{ml}$ volumetric flask and diluting with sample solvent (18 g potassium phosphate monobasic dissolved in 11 water).

\subsection{Colour measurements}

The colour measurements were performed with a UVIKON 933 spectrophotometer at $450 \mathrm{~nm}$. Millipore Q Water was used as a reference. Sam-

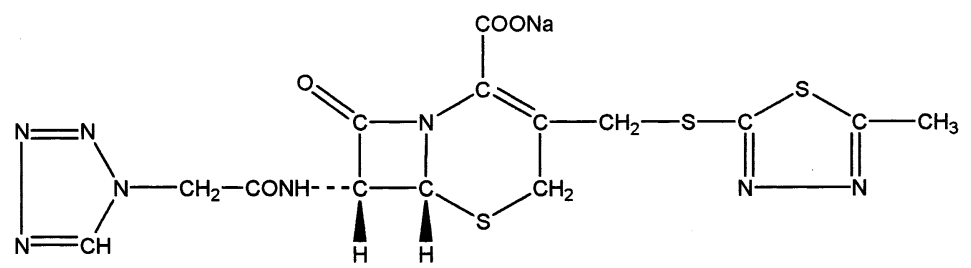

Cefazolin Sodium : (6R,7R)-3-[(5-methyl-1,3,4-thiazol-2-yl)thio]-methyl]-8-oxo-7-[2-(1Htetrazol-1-yl)acetamido]-5-thia-1-azabicyclo[4.2.0]oct-2-ene-2-carboxylate

Fig. 1. Chemical structure of cefazolin sodium. 


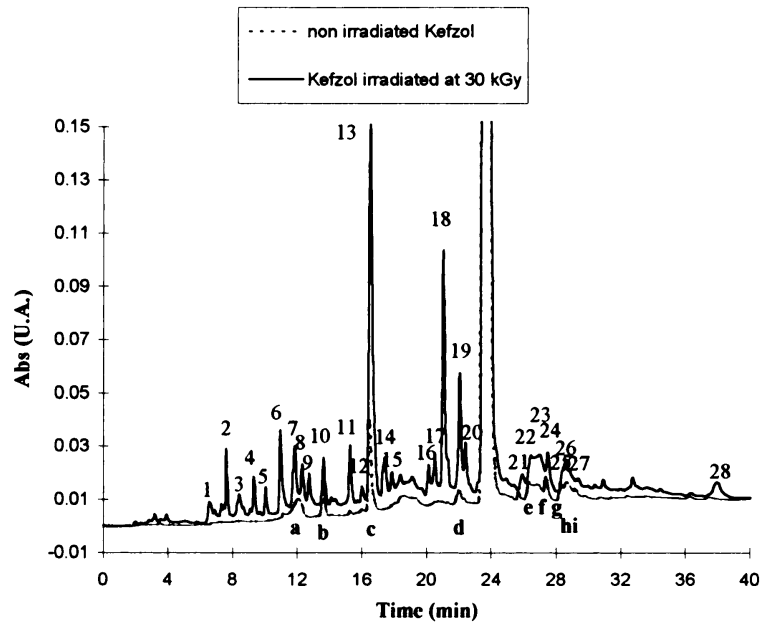

Fig. 2. A chromatographic profile (H.P.L.C.) with UV-detection $(\lambda 220 \mathrm{~nm}$ ) (letters and broken line: before radiolysis, arabic numerals and continuous line: after an irradiation at 30 $\mathrm{kGy}$ ).

ples were prepared by weighing $200 \mathrm{mg}$ of Kef$\mathrm{zol}^{\circledR}$ into a $2 \mathrm{ml}$ volumetric flask and diluting with water.

\section{6. pH Measurements}

The measurements were performed with a $\mathrm{pH}-$ meter HI 9025. Samples were prepared by weighing $200 \mathrm{mg}$ of $\mathrm{Kefzol}^{\circledR}$ into a $2 \mathrm{ml}$ volumetric flask and diluting with water.

\section{Results and discussion}

\subsection{Potency}

An overall estimation of the radiosensitivity was obtained by measuring the potency after 25 $\mathrm{kGy}$. It should be noted that $25 \mathrm{kGy}$ is quite a high irradiation dose for sterilizing pharmaceuticals. The bioburden is generally low and doses of about $10 \mathrm{kGy}$ are sufficient to achieve a sterility assurance level (S.A.L.) of $10^{-6}$, as suggested by Dam et al. (1995) [1].

The potency of the irradiated samples at 25 $\mathrm{kGy}$ was $4 \pm 2 \%$ lower than the potency of the non irradiated samples. The radio-induced de- composition of cefazolin sodium by ionizing radiation was low and was found to be slightly higher than that measured by Jacobs (1983) [2] who concluded that "gamma radiation only slightly reduces the potency of cefazolin". Nevertheless, the irradiated samples met the specifications of the European Pharmacopoeia (1997) [3].

The first measurements concerning the potency and the products formed by radiolysis were carried out with different experimental conditions. Experiments carried out in dry ice with $\gamma$ rays showed a potency loss reduced by a factor of 10 compared to those carried out at room temperature. Experiments conducted at room temperature, in the absence of air, showed a potency loss reduced by a factor of 3-6.

Two experiments using an electron beam generator showed that the loss of potency is reduced by a factor of 3-4 compared to $\gamma$ rays with the same absorbed dose. This result is surprising, and should be confirmed, because according to Willard (1987) [4] the effect of dose rate in the solid phase is negligible.

\subsection{Impurity profile}

The irradiation of $\mathrm{Kefzol}^{\circledR}$ (with cefazolin sodium as the active substance) produced new related substances. These radiolytic compounds were numerous and present in trace amount $(<$ $0.01 \%$ ) (represented by Arabic numerals on Fig. 2).

Some of the compounds (represented by letters on Fig. 2) were already detected in the non irradiated samples and were only increased by the irradiation ( $\mathrm{a}$ and $7, \mathrm{~b}$ and 10, $\mathrm{c}$ and 13, $\mathrm{d}$ and 19). Others were only detected after irradiation (1 to $6,8,9,11,12,14,15,16$ to 18 and 28).

Peaks 2 and 13 (or c) were identified by chromatographic coelutions as 7-aminocephalosporanic acid and methyl-11,2,3-thiazol-2 thiol-5, respectively. The other compounds, present in trace amounts, were not identified because the diode array detector doesn't give enough structural information compared to the mass detector. 
The total amount of related substances, calculated relatively to the UV response of cefazolin, increased from $0.72 \pm 0.01 \%$ in the non irradiated samples to $4.9 \pm 0.7 \%$ in the samples irradiated at $25 \mathrm{kGy}$. The peaks ranging from 22 to 24 (Fig. 2) represent $1.2 \pm 0.5 \%$ of the related substances. The European Pharmacopoeia defines that a related substance can not be present at more than $1 \%$. Irradiated samples nearly met this requirement. Specifications were given in $\%$ of the total area calculated with the same $\varepsilon$-value for UV-visible absortivity. Actually, one related compound was coloured and therefore the values of $\varepsilon$ may fall within a large range.

Nevertheless, the loss of potency is comparable to the increase of the impurity profile or the radiolytic products.

\section{3. $p H$ Measurements}

$\mathrm{pH}$ of non irradiated samples: $5.09 \pm 0.03$. $\mathrm{pH}$ of samples irradiated at $25 \mathrm{kGy}: 4.42 \pm$ 0.05 .

The $\mathrm{pH}$ of the cefazolin sodium solutions irradiated at $25 \mathrm{kGy}$ was lower than that of the non irradiated samples, but within the Pharmacopoeia specifications (between 4.0 and 6.0 (solution 100 $\mathrm{mg} / \mathrm{ml})$ ).

In a previous work on chloramphenicol, we observed that the solution became more acid after

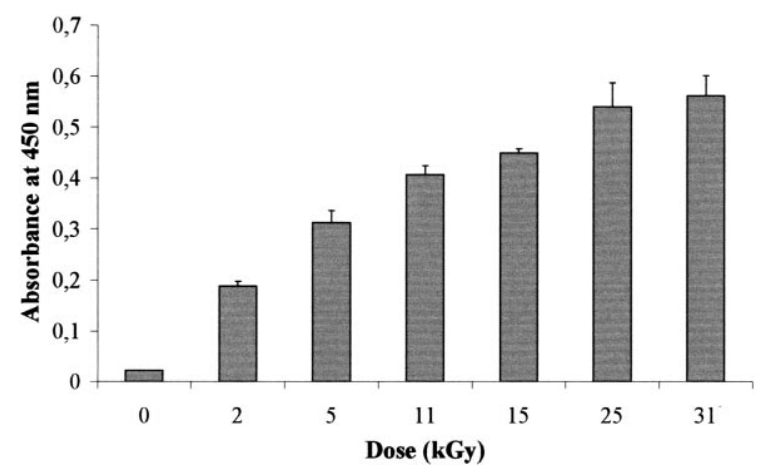

Fig. 3. Accumulation of coloured radiolytic product measured at $450 \mathrm{~nm}$ as a function of the dose. Irradiation of the solid, $200 \mathrm{mg}$ diluted in $2 \mathrm{ml}$ of aqueous solution. radiolysis and some carboxylic acids were identified by Zeegers et al. (1997) [5].

\subsection{Colour modification}

All the irradiated cefazolin samples became coloured: the powder turned yellow and the colour remained the same after dissolution. The colour change can be attributed to the radiolytic related substances which are yellow and these were estimated by measuring the absorbance of $100 \mathrm{mg} / \mathrm{ml} \mathrm{Kefzol} \mathrm{solutions} \mathrm{at} 450 \mathrm{~nm}$. Even a low irradiation dose ( $2 \mathrm{kGy})$ induced a significant absorbance at $450 \mathrm{~nm}$ (see Fig. 3) and was out of the specifications of the Pharmacopoeia.

The colour change could correspond to a chemical change of saturated compounds to unsaturated compounds. This type of radiolytic product can be formed by a disproportion radical-radical reaction. Radical mechanisms as studied by esr measurements, were to be considered in the radiolysis of molecular solids as studied by Gibella et al. (1999) [6].

In order to apply even low doses of radiosterilization $(10 \mathrm{kGy})$, we have to explain the mechanism(s) responsible for the production of unsaturated compounds so that we may be able to reduce or prevent their formation.

\section{Conclusion}

The tests used to estimate the radiosensitivity of Kefzol (potency, impurity profile, $\mathrm{pH}$ ) did not show a limitation for its radiosterilization. However, the feasibility of the radiosterilization is limited by the yellow colour change of the irradiated samples. A colour change was observed for many pharmaceuticals, European Pharmacopoeia (1997) [3], Schüttler et al. (1993) [7] [8]: most of the irradiated samples met the Pharmacopoeia's requirements, except those relating to the colour of the solution. In all the experiments, the potential toxicity must be neglected, the radiolytic products are present in traces. So, we have to define new specifications adapted for radiosterilization. 


\section{Acknowledgements}

This work was supported by Eli Lilly S.A.

\section{References}

[1] A.M. Dam, L.G. Gazso, S. Kaewpila, et al., Radiation sterilization dose calculation for heparin and apoprotin on ISO method, Int. J. Pharm. 121 (1995) 245-248.

[2] G.P. Jacobs, Stability of cefazolin and other new cephalosporins following $\gamma$ irradiation, Int. J. Pharm. 17 (1983) 29-38.

[3] Council of Europe, European Pharmacopoeia, third ed., 1997, p. 573
[4] J.E. Willard, in: Farhataziz, M.A.J. Rodgers (Eds.) The Radiation Chemistry of Organic Solids, Radiation Chemistry - Principles and Applications, USA, 1987, pp. 395434.

[5] F. Zeegers, M. Gibella, B. Tilquin, Analysis of some products from the irradiation of solid chloramphenicol, Rad. Phys. Chem. 50 (1997) 149-153 and F. Zeegers, Thesis, UCL, Belgium, 1995.

[6] M. Gibella, et al., Electron spin resonance studies of some irradiated pharmaceuticals, Rad. Phys. Chem. 00 (1999) $1-8$.

[7] C. Schüttler, K.W. Bôgl, Influence of radiation treatment on pharmaceuticals - a review. 1. Morphine derivatives and other alkaloids, J. Rad. Steril. 1 (1) (1993) 43-82.

[8] C. Schüttler, K.W. Bôgl, Influence of radiation treatment on pharmaceuticals - a review. Part 2. Antibiotics, J. Rad. Ster. 1 (3) (1993) 229-262. 